\title{
EL ARTE DEL RELATO EN PÉREZ DE AYALA: APROXIMACIONES FORMALES
}

\author{
Miguel Angel Lozano Marco \\ Universidad de Alicante
}

Como sabemos, Ramón Pérez de Ayala publicó en sus años de plenitud creadora, entre 1902 y 1928 , medio centenar de narraciones breves; precisamente estos veintiséis fecundos años se hallan acotados por dos novelas cortas: la inencontrada Trece dioses, la primera que escribió según confesión propia (1), y Justicia (1928), que señala el punto final de su carrera como narrador. Los relatos fueron apareciendo en las páginas de la prensa periódica, en diarios, revistas y colecciones de novelas cortas, para después encontrar acomodo en diversos volúmenes no exentos de originalidad en su deseo de rehuir la condición de meras recopila-

(1) Conocemos la existencia de esta novela corta desde que fue citada en la incompleta biografía de Miguel Pérez Ferrero, Ramón Pérez de Ayala, Madrid. Publicaciones de la Fundación Juan March - Guadarrama, 1973. En la pág. 72 se nos dice que el escritor asturiano se inspiró en la Sonata de otoño, libro que habla recibido, con la dedicatoria de Valle-Inclán, cuando todavia era estudiante en la Universidad de Oviedo lo sea, antes del verano de 1902); el relato fue publicado en el periódico El Porvenir de Asturias, según precisa Pérez Ferrero. No ha sido encontrado hasta el momento. 
ciones de cuentos: Prometeo, Luz de Domingo, La caída de los Limones. Tres novelas poemáticas de la vida española (1916), Bajo el signo de Artemisa (1924, aunque los seis relatos que reúne fueron publicados entre 1903 y 1912), El ombligo del mundo (1924; cinco narraciones y un prólogo unificadorl. Otro volumen de novelas cortas fue publicado por la editorial Losada de Buenos Aires en 1959, parece ser que a instancias de Guillermo de Torre (2), y recoge, bajo el rótulo de La revolución sentimental, tres novelas cortas (fechadas en 1913, 1922 y 1928) no reunidas anteriormente, junto con la obrita de teatro que le da título. Años después, en 1962, José García Mercadal recopila y publica en un tomo con el título de El Raposín veintidós cuentos escritos entre 1903 y 1924, de los que la casi totalidad son obras primerizas fechadas (o fechables) antes de 1907. Algunos relatos no pasaron a las páginas de un libro hasta su inclusión en las Obras completas de la editorial Aguilar: El último vástago, La fiesta del árbol, Sonreia (3); Cuarto menguante quedó fuera de ellas puesto que, después de sufrir una adecuada reelaboración y ampliación, se convirtió en la primera parte de la novela Luna de miel, luna de hiel (4). Por último hay que señalar que en otras secciones de las citadas Obras completas encontramos algún relato más: en La caverna de Platón son claramente cuentos la obrita que abre la sección (y que le da título) y Un mártir (5), mientras que en un par de crónicas de Terranova y sus cosas advertimos un predominio de lo narrativo (6), lo que las acerca al campo objeto de este trabajo.

(2) Vide Guillermo de Torre, "Un arcaizante moderno: Ramón Pérez de Ayala" en La diffcil universalidad española, Madrid, Gredos, 1965, págs. 163-199; la referencia en el texto corresponde a la pág. 178.

(3) El último vástago fue publicada en 1905 por la revista Hojas Selectas de Barcelona y totalmente olvidada hasta su descubrimiento por Joaquín Forradellas lerEl último vástago, novela primera de Pérez de Ayalan, Letras de Deusto, $n^{\circ} 9$ (enero-junio, 1975), págs. 137155. Es una de las obras más imperfectas de su autor: formalmente viene a ser un producto híbrido de nouvelle y romn pues emplea los procedimientos de la novela dentro de las dimensiones de una novela corta, con lo que todo queda notablemente desequilibrado. Esta novela, junto con La fiesta del árbol y algún escrito más, no narrativo, ha sido incorporada a la segunda edición del vol. I de las Obras completas (Madrid, Aguilar, 1973) notablemente enriquecido con respecto a la primera, de 1964. Los relatos se encuentran recogidos en el citado vol. I y en el vol. II (1965).

(4) Cuarto menguante fue publicada en el núm. 14 de La Novela Semana/ (Madrid, 1921) y conserva el mismo título al pasar a la novela como su primera parte.

(5) Aparecidas en El Gráfico en junio y julio de 1904; en O.C., I, págs. 1275-1278 y 1295 1299. Estas obritas ya hablan sido consideradas como cuentos por Sara Suárez Solís, Análisis de "Belarmino y Apolonio", Oviedo, Instituto de Estudios Asturianos, 1974.

(6) Fueron publicadas en el "Glosario de los cronistas" del Heraldo de Madrid, desde el 6 de enero de 1911 hasta el 5 de julio del mismo affo. Recogidas en O.C., I, págs. 13391404. 
En las páginas siguientes voy a intentar esbozar algunos rasgos generales, apuntar algunas de las características formales que presenta la narrativa breve de Pérez de Ayala, un sector de su producción literaria poco atendido por la crítica (7). Este sector incluye, como hemos visto, cuentos y novelas cortas, y ambas denominaciones hacen referencia a dos realidades literarias con sus peculiaridades propias, pero también con estrechas afinidades. El profesor Mariano Baquero Goyanes ha puesto de manifesto a lo largo de sus esclarecedores estudios el cercano parentesco existente entre estos dos tipos de narraciones. En su fundamental Tesis nos decía:

Quitada la extensión, no puede apreciarse diferencia de técnica o de intención estética entre cuento y novela corta...

En efecto, la técnica es la misma: Maupassant, la Pardo Bazán, Clarín componen novelas cortas y cuentos sirviéndose de un mismo procedimiento, consiguiendo idéntico tono en unas y otros. La novela corta y el cuento se ven de una vez, y se narran sin interferencias, sin digresiones, sin personajes secundarios. Sólo se diferencian en que el asunto de la novela corta - que, en los mejores casos, tiene una raíz poética semejante a la del cuento, $v$. gr., Doña Berta de Clarín - requiere más páginas (8).

$Y$ en un reciente artículo vuelve a tocar el tema, defendiendo como más apropiado el término cuento largo, utilizado por la Pardo Bazán para referirse a lo que más comúnmente conocemos como novela corta:

De haber prevalecido la otra designación, la fugazmente manejada por Emilia Pardo Bazán, se habría aclarado una, para mí, cuestión fundamental: la diferencia entre cuento, novela corta y novela, reside en algo más que una simple cuestión de número de páginas. Lo que entendemos por novela corta está bastante más

(7) Cuando estas páginas se encontraban ya redactadas ha sido publicada una edición crítica de El ombligo del mundo realizada por Angeles Prado (Madrid, ed. Origenes, 1982), quien ya nos habia ofrecido unrexcelente artículo, "Las novelas poemáticas de Ramón Pérez de Ayala». (Cuadernos Hispanoamericanos, núms. 367-68, enero-febrero de 1981, págs. 41-70). Se hace obligado citarlas como las mejores contribúciones al estudio de la narrativa breve ayaliana.

(8) El cuento español en el siglo XIX, Madrid, C.S.I.C., 1949, pág. 109. En la pág. 113 señala "Las dimensiones están en la novela al servicio del conjunto - personajes accesorios, descripciones, interferencias-, y en el cuento y la novela corta, al del argumento exclusivamente. De la extensión de éste depende el que la narración sea uno u otro género». 
cerca del cuento que de la novela sin más. Por eso, el término sugerido por la Condesa de Pardo Bazán hubiera resultado más definidor y expresivo, en la medida en que señalaba, con mayor precisión, un entronque o parentesco literario (9).

Entrando en materia, es preciso señalar en primer lugar que estos relatos suelen responder al esquema estructural más común: cada uno de ellos narra una historia, con su presentación, conflicto y desenlace; historia que en los cuentos se reduce a una breve anécdota, y casi llega a desaparecer en los relatos de tipo simbolista (los más tempranos), pues en éstos interesa más la creación de un ambiente sugestivo, producir ciertas sensaciones, etc... El desenlace suele ser rápido, abrupto y, con cierta frecuencia, brutal, en la línea de las mejores obras de Clarín y de los finales efectistas de Valle-Inclán (10).

La cualidad predominante, a mi juicio, en los relatos de Ayala es la que ha sido señalada por María del Carmen Bobes para resaltar aquello en lo que radica el aspecto renovador de su novelística - sería común, pues, a sus novelas, novelas cortas y cuentos-; su «especial tratamiento del tiempo», «la forma de presentar personajes y de situar el relato en un tiempo presente", con lo que crea uimpresión de inmediatez» (11); aunque, en realidad, esto sitúa a Pérez de Ayala en su contexto histórico-literario, puesto que es una característica propia de la novela del primer cuarto de siglo, advertida por Ortega y Gasset en su conocidísimo ensayo /deas sobre la novela (1924): «el género se ha ido desplazando de la pura narración, que era sólo alusiva, a la vigorosa presentación... De narrativo o indirecto se ha ido haciendo el género

(9) "Los 'cuentos largos' de 'Clarín'», Los Cuadernos del Norte, n’ 7, (mayo-junio, 1981), págs. 68-71. La cita corresponde a la pág. 68.

(10) Hay que tener en cuenta que don Leopoldo Alas y don Ramón del Valle-Incián son los que ejercen un magisterio más directo sobre el Pérez de Ayala autor de relatos. La huella del escritor gallego se percibe en varias ocasiones: en el simbolismo y decandentismo de sus primeros relatos y en el aire de comedias bárbaras que respiran Exodo y Padre e hijo. Sobre la relación Clarln - Pérez de Ayala, vide Mariano Baquero Goyanes, "Los cuentos de 'Clarín'", recogido en J. M" Martínez Cachero, Leopoldo Alas "Clarín", Madrid, Taurus, 1978, págs. 245-252; interesantes referencias sobre este tema en Laura de los Ríos, Los cuentos de "Clarín». Proyección de una vida, Madrid, Revista de Occidente, 1965.

(11) María del Carmen Bobes Naves, "Técnicas cinematográficas en las primeras novelas de Ramón Pérez de Ayala», Los Cuadernos de/ Norte, núm. 2 (junio-julio, 1980), págs. 26-29. Sobre el carácter presentativo de la novelistica ayaliana y su utilización del tiempo vide su art. "Sintaxis temporal en las primeras novelas de Ramón Pérez de Ayala", Insula, núms. 404-405 (julio-agosto, 1980), págs. 1 y 30. 
descriptivo o directo. Fuera mejor decir presentativo (12)m. Nuestro autor incide repetidamente sobre esta misma idea: sus novelas se proponen «la recreación presente» (13); "ir trazando y presentando» (14); el "análisis de la dura realidad y de las verdades amargas y presentes cotidianos» (15), etc... Es fácil observar, al acercarnos a cualquier novela de Ayala, desde Tinieblas en las cumbres hasta El curandero de su honra, ese desarrollo presentativo de la trama, la evolución de la conciencia del personaje manifestándose ante nuestros ojos, etc... El profesor Baquero hace hincapié en este aspecto, advirtiendo cierta vinculación de estas novelas con el teatro:

Cualquier lector atento descubrirá en las novelas de Ramón Pérez de Ayala una muy peculiar textura teatral, perceptible en temas, situaciones, diálogos y modalidades descriptivas. Los valores que afectan a la pureza novelesca no quedan mermados, sin embargo, con esa carga de elementos teatrales (16).

En general, lo apuntado para la novela reza también para la narrativa breve, con las salvedades que indicaremos. No hay más que acudir al primer cuento conocido, El otro padre Francisco, para advertir su evidente construcción teatral: son dos escenas, con una buena descripción del escenario, situación central de los protagonistas, movimiento y diálogos de tipo escénico, etc. Del mismo modo, recordemos la índole dramática de Artemisa, la primera novela corta escrita para El Cuento Semanal (17).

Este carácter presentativo de la narrativa ayaliana se manifiesta, en el sector que aqui estudiamos, bajo la forma de una modalidad típi-

(12) Meditaciones del Quijote. Ideas sobre la novela, Madrid, ed. Espasa-Calpe, 1976 (3* ed.), pág. 165.

(13) "Prólogo» a Troteras y danzaderas, Buenos Aires, ed. Losada, 1942, pág. 19.

(14) ibid., pág. 13.

(15) Ibid., pág. 18

(16) Mariano Baquero Goyanes, "La novela como tragicomedia: Pérez de Ayala y Ortegan, en Perspectivismo y contraste (De Cadalso a Pérez de Ayala), Madrid, ed. Gredos, 1963, pág. 161.

(17) Artemise se subtitula Novela dramática y fue publicada en 1907 en la citada revista; al parecer respondla Pérez de Ayala a una invitación hecha por José López Pinillos "Parmeno", según se desprende de una carta de este último dada a conocer por José García Mercadal en el prólogo titulado "Una amistad y varias cartas», que figura al frente de la colección de ensayos ayalianos Ante Azorín, Madrid, Biblioteca Nueva, 1964, págs. 7-44. La citada carta puede leerse en la pág. 15. 
camente contemporánea: el cuento-situación (18). Si en el cuento más puramente decimonónico era el argumento -como lo ha sido tradicionalmente - el elemento decisivo y primordial, después del naturalismo, la atención prestada a escenas cotidianas $y$, más decisivamente, a la psicología de los personajes - con la necesidad de captar el momento significativo que nos alumbra una vida - , y la necesaria técnica impresionista que de ello se deriva y que va prevaleciendo en la visión del mundo exterior, origina la creación de unos cuentos que inciden sobre una situación o un suceso de reducidas dimensiones temporales - ese momento significativo al que hemos aludido-, y de espacio también limitado. Así, casi la totalidad de los cuentos de Pérez de Ayala narra un suceso que se desarrolla en un corto período de tiempc o, si éste se dilata, escoge unos instantes decisivos: cuentos como Don Paciano, El patriarca, La fuerza moral, Don Rodrigo y don Recaredo, La espalera, Quería morir, La caverna de Platón..., relatan un suceso ocurrido en muy pocas horas; sólo una noche ocupa el desarrollo de las historias de Espiritu recio, La última aventura de "Raposín», La prueba; o un día, Miguelín y "Margarita"; y en momentos decisivos -y aislados - se nos van dando a conocer los acontecimientos en $E I$ otro padre Francisco, El Raposín. Tio Rafael de Vaquín, La nación, Viudo (escrito en forma de diario), Iniciación, La primera grieta, etc.

En las novelas cortas, las historias ocupan un desarrollo temporal más dilatado, con la excepción de Artemisa, y Pandorga, esta última a causa de su disposición teatral: "Escenario», "Entremés» y «Drama» se titulan las tres partes en que está dividida. Resulta interesante ver cómo Artemisa, escrita en la época en que iban viendo la luz casi todos estos cuentos, participa de las cualidades del relato-situación: la historia abarca una velada y la mañana siguiente, mientras que todas las novelas cortas posteriores seguirán ya la línea apuntada. No es necesario comentar, en este sentido, el caso de Sentimental Club, pues se trata de una pieza teatral en la que se representa, en un cuadro único, una conversación entre diez personajes (19).

Muy unido con el carácter presentativo de los relatos y con la abun-

(18) Vide M. Baquero Goyanes, El cuento español... Incide más el citado crítico sobre las características del cuento-situación en su art. "Los cuentos de Baroja", Cuadernos Hispanoamericanos, núms. 265-267 (julio-septiembre, 1972), págs. 408-426. Sobre esta misma modalidad de relatos: Eran Brandenberger, Estudios sobre el cuento español contemporáneo, Madrid, Editora Nacional, 1973, págs. 280-281, y Mirella D'Ambrosio de Servodidio, Azorín, escritor de cuentos, New York-Madrid, Las Americas Publishing Company-Anaya, 1971. 
dancia de cuentos de situación nos aparece el problema de las voces narradoras, la presencia del narrador. Tradicionalmente, el cuento requiere ser "contado" por alguien, necesita de una voz en la que se centre nuestra atención y que organice de una manera interesante los acontecimientos; pero esta voz ocupa siempre un primer plano, sobreponiéndose a la propia historia narrada y a los personajes, de manera que la figura del relator ha estado presente en todo cuento, a lo largo de la historia, desde sus primeras manifestaciones - Las mil y una noches, El conde Lucanor, etc. - hasta finales del siglo XIX. Es fácil observar cómo en los mejores cuentos de Clarín el relator se mantiene siempre en primer plano, subrayando su presencia continuamente: da opiniones, completa ideas, ve a los personajes por fuera y por dentro describiéndonos sus pensamientos y haciendo comentarios sobre ellos...; véanse obras como Pipá, Las dos cajas o Doña Berta, por sólo poner tres ejemplos. Pues bien, el narrador objetivo e imparcial de la novela naturalista invade también el terreno del relato breve, dando como resultado los que Juan Paredes Núñez denomina "cuentos directos», es decir, cuentos sin narrador designado en los que «la historia que se narra llega a nosotros directamente, en su forma originaria, sin pasar por el tamiz subjetivo del relator') (20). Aunque el tipo de narrador omnisciente que aparece en toda la narrativa de Pérez de Ayala acostumbra a tener alguna intervención, señalando su presencia, sin embargo en la mayor parte de sus relatos tiende a desaparecer esa voz narradora para que los sucesos nos sean presentados directamente.

En este sentido, hemos podido observar que siempre que un narrador en primera persona aparece llevando las riendas del relato, es su voz lo que prevalece sobre todo lo demás; es decir, en estos casos predomina la narración sobre la presentación; mientras que cuando es un narrador en tercera persona quien cuenta el suceso, tiende a presentar, y aparece muy escasamente. Asi, encontramos un "yo narrador" central en Quería morir - que tiende a la meditación -, y otros marginales, que

(19) La pieza ha sido objeto de un análisis formal por parte de Joaquina Canoa Galiana, "Pérez de Ayala y el teatro", Homenaje a Ramón Pérez de Ayala, Universidad de Oviedo, 1980, págs. 161-188. Un estudio de la obra, teniendo en cuenta las dos versiones (entre las que hay variantes muy significativas), ha sido realizado por Ignacio Soldevilla-Durante, "Ramón Pérez de Ayala: De Seritimental Club a La revolución sentimental», Cusdernos Hispanoamericanos, núm. 181, 1965, págs. 5-19; recientemente ha vuelto sobre el tema, viéndolo a nueva luz, en el art. "Una cuestión poética y una pregunta retórica en torno a Sentimental Clubu,, en Pelayo H. Fernández, ed., Simposio Internacional Ramón Pérez de Ayala, University of New Mexico (Gijón, 1981), págs. 136-147.

(20) Juan Paredes Núñez, Los cuentos de Emilia Pardo Bazán, Universidad de Granada, 1979 , pág. 362. 
reproducen las opiniones de un personaje central (La caverna de Platón); o nos relata el caso singular de un hombre al que conoce directamente (Un mártir); o se nos muestra como receptor - y apostillador de una historia narrada en tercera persona por un amigo (Lá fiesta del árbol). En otras ocasiones, el narrador es un personaje que escribe un diario (Viudo); o relata unos sucesos, en los que no interviene, que intenta çontar con objetividad (Tío Rafael de Vaquín); o traza unas páginas autobiográficas (Sonreía); o interviene en una tertulia, expresándose mediante apólogos (La araña). En una ocasión nos aparece el autor disponiéndose a narrar un cuentecillo popular - casi un chiste-, acto que realiza después de un preámbulo de tono evidentemente ensayístico (El delirio) (21). El resto de los relatos sigue la línea antes apuntada: tendencia a la presentación, que en ocasiones llega a objetivar la acción acercándose a formas teatrales (22), y esporádicas intromisiones del narrador.

(21) Es uno de los casos de máxima concentración: el cuentecillo tiene un carácter evidentemente oral, popular. Del mismo modo, y con el apropiado gracejo, nos cuenta Pérez de Ayala un chiste o cuentecillo que no me resisto a apuntar aquí. No aparece en un contexto de narraciones, sino introducido en un artículo que puede leerse en el libro $P e$ queños ensayos, Madrid, Biblioteca Nueva, 1963; en págs. $72-75$ encontramos el art. titulado "Por ser cojo", que comienza: "Casi todos conocen aquel cuentecillo que reza así: 'Era un ricacho que tenía suntuoso palacio, más para mover la admiración y envidia de quienes le visitaban que para gozar de él. Tenialo abierto en todo punto a quienes quisieran visitarlo, y gustaba él mismo de mostrarlo, a modo de guía de museo, celoso de encarecer sus bellezas $y$ fastuosidades, $y$, sobre todo, de que no le tocasen y estropeasen nada. Artesones, pinturas, esculturas, mármoles y bronces, todo era de mucho precio y primor. Pero lo que más le enorgullecía eran los tillados, taraceados con las maderas más ricas y exóticas, pulimentados como lunas de Venecia. No consentía que nadie los pisase, y por evitarlo habia tendido al paso mullida alfombra de ruedo. Sucedió que un general, su amigo, vino a visitarle y a visitar el palacio. Era un bravo y desenvuelto militar que usaba una pierna de palo, habiendo perdido la suya propia en una acción de guerra. 'Por aqui, por la alfombra', decía el ricacho señalando el camino. Pero el general, como si nada oyese, metíase por el tillado, andando de un lado para otro y levantando con el palo de la falsa pierna un ruido deplorable que al ricacho le hacía eco en el corazón. No sabiendo cómo atajar el mal, el ricacho suplicó: 'Por Dios, general, no ande usted sobre el tillado, que va a resbalar'. En esto, el general se volvió sonriente, levantó en el aire con prodigioso alarde de equilibrio la pierna de palo, hasta mostrar al ricacho una formidable contera puntiaguda y respondió: '¡Quía! Llevo un buen pincho'. La historia no concluye así: como es de presumir, al ricacho le dio un soponcio».

(22) Además de los relatos citados, que presentan evidentes rasgos teatrales (E) otro padre Francisco, Artemisa, Pandorgal, habria que mencionar no sólo obras de clara disposición teatral (La dama negra, Sentimental Club), sino también gran número de cuentos y de novelas cortas en que aparecen verdaderas escenas: Exodo, La araña, La caída de los Limones, Don Rodrigo y don Recaredo, La fuerza moral, Pilares, La triste Adriana, El árbol genealógico, Tio Rafael de Vaquin,... Es fácil para cualquier lector de los relatos de Ayala comprobar to que aqui se afirma. 
Es una idea generalizada, por obvia, el achacar a las creaciones ayalianas una excesiva carga intelectual, resuelta en ensayismo, o un determinado tono que implica la presencia y la postura de su autor. A lo segundo habría que responder con la acertada conclusión de Wayne $C$. Booth: «el juicio del autor está siempre presente y es siempre evidente para cualquiera que sepa cómo buscarlo. Si sus formas particulares son perjudiciales o aprovechables es siempre una cuestión compleja, que no puede determinarse con una fácil referencia a reglas abstractas» (23). En cuanto a lo primero, a la presencia del ensayismo en sus relatos, podemos asegurar que, contrariamente a lo que suele suceder en sus novelas, es muy escasa, pues la misma índole de este tipo de narrativa le obliga a contar una historia y a no desviar la atención por senderos ajenos a la acción que allí acontece. En sus cuentos y novelas cortas encontramos al narrador inequívoco, dotado de una maestría en el manejo de los resortes narrativos que nadie puede poner en cuestión; por ello, el tipo de objeciones hechas a sus novelas a partir de los juicios de Cansinos-Assens no es válido para este sector (24). No hay más que recordar sus más felices relatos (LUz de domingo, La caída de los Limones, La triste Adriana, El profesor auxiliar, Justicia, Espíritu recio, Un instante de amor, ...) para evidenciar lo antedicho: ausencia de ensayismo - entendido como la irrupción de meditaciones sobre diversos temas - y plenitud de los procedimientos propios de la narrativa, lo que da como resultado unas obras perfectas en su género. Desde luego, estos cuentos y novelas cortas participan de las preocupaciones básicas que su autor manifiesta en los diversos géneros literarios por él cultivados, y por ello no son obras que existan por sí mismas, como creaciones que son fruto de una intuición artística única, sino en función del pensa-

(23) Wayne C. Booth, La retórica de la ficción, Barcelona, Bosch, Casa Editorial, S.A., 1974, pág. 19. La conclusión citada viene precedida por una completa enumeración de "las muchas voces» que puede adoptar el autor, la variedad de formas en que éste puede hacer su aparición; y añade una concisa sentencia: «...aunque el autor puede hasta cierto punto elegir sus disfraces, él nunca puede elegir el desaparecern.

(24) Rafael Cansinos-Assens, "Ramón Pérez de Ayala», en La nueva literatura. IV. La evolución de la novela. Colección de estudios críticos, Madrid, ed. Páez, 1927. En págs. 102-103 se pregunta: " ¿ Son verdaderas novelas, en el sentido moderno de la palabra, esos frutos de su ingenio, que con tal título nos brinda, $y$ en todo caso, puede considerársele un maestro de ese género literario?"; $y$, a continuación, se responde: "es lo cierto que cuando se habla de él siempre surge cierta necesidad de modificar en algún modo la rotunda rotulación genérica que sin salvedades empleamos cuando se trata de otros escritores. El mismo da muestras de perplejidad, al clasificar sus obras narrativas, llamándolas 'novelas dramáticas', 'tragicomedias', etc.). Para este crítico, la característica esencial de estos escritos es su hibridez: no duda en afirmar que Ayala está «más o menos» fuera del género novelístico, y concluye en pág. 106: «En Pérez de Ayala predominan siempre el poeta, el ensayista, sobre el novelador». 
miento que las origina y les da un sentido (25). Sin embargo, de cara al lector y en las narraciones más logradas (piénsese en los títulos arriba citados) la carga ideológica no suele prevalecer sobre lo narrado, quitando vida a lo que acontece, sino que de la pura narración de unos hechos se desprenden unas consecuencias éticas: el reconocimiento de la normativa a la que se ha de adecuar la conducta humana para alcanzar su plenitud o el fracaso que determina el incumplimiento de dicha normativa, al tiempo que se hace evidente su fundamento metafísico, la visión del universo concebido como una multiplicidad de contrarios que se armonizan desde una perspectiva superior, abarcadora de la creación entera, donde cada ser "obedece a una fatalidad que le ha sido impuesta» (26). Podemos concluir, pues, que en estas obras encontramos la perfecta y equilibrada unión de los tres elementos básicos que, a mi juicio, constituyen el relato original ayaliano: lo poemático, lo ensayístico - concebido aquí como la estructuración ideológica que precede a la creación literaria, y no sólo como mero aditamento de digresiones meditativas - y lo novelesco (27) se amalgaman en una obra en la que el tercer elemento no sufre merma de lo que le es propio y sustancial, sino que predomina y resulta notablemente enriquecido por los otros dos; aunque en algún caso - que suele ser muy raro- la preexistente organización intencional se deje sentir con más intensidad llevando la acción hacia un desenlace necesario, si atendemos al sentido de la obra, pero que no deja de causar cierta extrañeza: me refiero al caso de Prometeo, novela en la que el diseño ideológico se sobrepone al desarrollo de los acontecimientos, gobernándolos fatalmente (28).

El ensayo propiamente dicho, es decir, la exposición de ideas sobre

(25) El mismo Pérez de Ayala nos ofrece la siguiente distinción: «Es de sentido común que hay dos categorias de autores: unos que no hacen sino lo que pueden hacer; otros que hacen aquello que creen que deben hacer. Es decir, los productores intuitivos, inconscientes, inspirados; y los escritores con estética personal meditada» (“El periodismo literarion, en Divagaciones literarias, O.C., IV, pág. 1001).

(26) R. Pérez de Ayala, «El liberalismo y La loca de la casa», Las máscaras, en O.C., III, pág. 52.

(27) $\mathrm{He}$ intentado apuntar concisamente en el texto la entidad del elemento ensayístico en las mejores narraciones del escritor asturiano: la misma disposición del texto, construido sobre unas ideas que van tomando cuerpo en personajes y acciones, $y$ encauzando hacia unas conclusiones determinadas. De la misma manera, el elemento poemático no se reduce a la inclusión de poemas, ni a un determinado tono lírico de la prosa. Con el calificativo de "poemático» aplicado a lo narrativo se alude a lo que constituye lo más esencial, lo que define a la novelística ayaliana: su condición de obras de pura creación, de arte no reproductivo, como fue advertido inteligentemente por César Barja en su estudio «Pérez de Ayala", en Literatura española: libros y autores contemporáneos, Madrid, Victoriano Suárez, 1935, págs. 439-466. 
un determinado tema, no abunda en los relatos ayalianos, pero tampoco está ausente del todo. Suele aparecer, cuando lo hace, de dos maneras: directamente, en boca del narrador -o del «yo narrador»-, o en boca de un personaje razonante que medita y discursea; uno de esos personajes puramente cerebrales. A la primera modalidad pertenece uno de sus relatos más antiguos, Quería morir, cuyo centro está constituido por unas meditaciones del "yo narrador»; asimismo, el narrador expone sus ideas y argumenta en el preámbulo de El delirio y en los primeros capitulos de El Anticristo y de Pandorga - «Escenario»-: lo ensayistico, en estos casos, suele preceder a la acción y cumplir un cometido caracterizador desde un principio, formando parte de la presentación de la trama. En la segunda manera nos encontramos con unos personajes hipercríticos, que suelen expresarse en forma de discurso ensayistico; éstos son don Melitón Pelayo (29) en La caverna de Platón, el duque don Anselmo en El árbol genealógico Y, sobre todo, el señor Hurtado en Clib, novela en la que también su protagonista, Generoso Vigil, propende a la reflexión. Es preciso citar, en este lugar, al Sentiñano de la novela inconclusa Pilares, asi como al Marco-Juan Pérez de Setiñano de Prometeo, aunque en estos casos las exposiciones de su pensamiento no tienden a la divagación ni toman nunca forma de digresiones, sino que se encuentran perfectamente adaptadas a la trama de la novela, siendo partes esenciales de la misma. De las dos modalidades - narrador y personajes reflexivos - participa uno de los relatos más cerebrales y más complejos: La araña (30). Poca cosa más se puede añadir a los títulos aquí citados, y una labor de rastreo aportaría sólo algunos párrafos aislados que nada añaden a lo dicho.

Muy cercanas al cuento, y participando también del tono meditativo y discursivo del ensayo, se encuentran unas pocas obras con las que he creido oportuno enriquecer, aunque sea mínimamente, el campo aquí

(28) Asi, Eugenio G. de Nora, ante el desenlace de Prometeo, opina: "Caso, podría pensarse, de fatalidad trágica, antes que de lógica novelesca. Pero aún ese efecto, si es el que se pretende, no está del todo logrado» ("Ramón Pérez de Ayala», en La nove/a española contemporánea (1898-1927), vol I, Madrid, ed. Gredos, 1973 (2ª ed.), pág. 488.

(29) Véase el sentido que este personaje tiene én los primeros af́os de actividad literaria de su creador en el excelente art. de Angeles Prado «Seudónimos tempranos de Pérez de Ayala», Insu/a, núms. 404-405 (julio-agosto, 1980), págs. 1, 18 y 19.

(30) Publicada en el núm. 9 de El Libro Popular (4 de marzo de 1913). Julio Matas en su estudio Contra el honor. Las novelas normativas de Ramón Pérez de Ayala, Madrid, Seminarios y Ediciones, S.A., 1974, subraya el interés de esta novelita a la hora de estudiar la evolución de la obra y el pensamiento de su autor, pues afirma que en ella "ya se encuentran en germen los elementos de las futuras novelas mayores» (vide esp. págs. 32$38)$. 
estudiado: tres de las crónicas de Terranova y sus cosas, el artículo La fiesta del árbol y El pueblo. El hombre. El Asno. Estampa. La crónica es un género literario propio de la prensa periódica, que tuvo gran vitalidad en la época modernista: José Carlos Mainer nos da de ella una definición sintética y precisa: «mezcla afortunada de impresión vivida, cuento inconcluso y ensayo personal» (31). De las dieciocho crónicas que aparecen en la agrupación antes citada - cumpliendo lo señalado en la definición del profesor Mainer-, Mascarita: ¿me conoces?, Suprema entrevista y La vieja y la niña manifiestan una evidente forma de relato por el predominio de lo narrativo sobre los otros elementos. El contenido de La fiesta del árbo/ no responde a lo designado por el subtítulo con el que aparece en las Obras completas: "Artículo»; la historia que ese amigo sin nombre cuenta al "yo narrador» es un cuento con todas las de la ley, al que no merma en su esencia el carácter crítico del relato, la referencia a determinados políticos de la época ni, mucho menos, la moraleja final. Por el contrario, El pueblo. El hombre. El asno... responde perfectamente al término con el que se designa su forma literaria: es una estampa (32).

(31) La Edad de Plata (1902-1931). Ensayo de interpretación de un procéso cultural, Barcelona, Los Libros de la Frontera, 1975, pág. 39. En escritores de la época finisecular la crónica toma, a veces, forma de cuento; así lo ha observado Allen Phillips en su excelente estudio Alejandro Sawa, mito y realidad, Madrid, Ediciones Turner, 1976, vide esp. págs. 240-241, 244-247 y 292-309.

(32) No recogida en O.C. Fue publicada en El Sol, 19 de septiembre de 1920, pág. 1. 